\section{Beating the plague}

\section{Len Goodwin}

Smallpox and its Eradication. By F Fenner, D. A. Henderson, I. Arita, Z. Ježek and I. D. Ladnyi. World Health Organization: 1988. Pp.1,460. SwFr. 250, $\$ 150, £ 80$

SMALLPOX was with us for a very long time - probably ever since the development of irrigated agriculture 10,000 years ago, which initiated the human population explosion that still continues today. The variola virus may have already existed among our primate ancestors, or have been derived from another animal orthopox virus, but it certainly got its opportunity when large numbers of people began to live in close contact. It had no alternative animal host, no insect vector and it produced lasting immunity: it could therefore only persist if enough susceptible human beings were available to maintain a continuous chain of infection. Smallpox was universally feared and, in the cities of Europe and Asia where records were kept, caused on the average 10 per cent of all deaths every year. These characteristics, together with an easily recognizable rash and the existence of a safe and effective method of immunization, made it possible to plan a world-wide campaign of eradication.

The elimination of smallpox was first mooted to the World Health Assembly in 1953 but the idea was turned down. Five years later a global eradication plan was accepted and put into operation. But although the disease was removed from some 30 countries, inadequate funding meant that the hard core in the Indian subcontinent and in Africa remained. In 1966 an intensified programme with better financial backup was instituted, and almost achieved its ambitious target of eradicating smallpox within ten years. In fact it took eleven; despite intensive surveillance, no endemic smallpox has been detected anywhere in the world since the last case in Somalia in October 1977.

Edward Jenner was largely responsible for the introduction of 'vaccination' with cowpox virus to replace 'variolation', a method that used material from the pustules or scabs of smallpox patients and carried a risk of up to 2 per cent mortality. In 1801 Jenner wrote: "the annihilation of the Small Pox, the most dreadful scourge of the human species, must be the final result of this practice". The fulfilment of his prophecy, 176 years later, represents a triumph for the World Health Organization and is meticulously celebrated in this great, big, beautiful book that took seven years to write.

The style is clear and interesting, there are hundreds of excellent colour plates, maps, tables, photographs of places and people, and plentiful 'boxes' containing summaries of the text. It is a worthy tribute to the work of Donald Henderson and his team. Everything is covered -early history, basic science, clinical aspects, pathology and immunology, vaccine production and application. There are detailed accounts of the complex operations, different in every country, which were developed for the effective deployment of thousands of local staff for the detection of cases, vaccination, follow-up and surveillance, often in remote and sometimes dangerous terrain. Vaccine was improved and stabilized, and

\section{IMAGE UNAVAILABLE FOR COPYRIGHT REASONS}

\section{This was smallpox}

its administration was facilitated by the introduction of a bifurcated needle that picked up the correct dose for inoculation. House to house searches for cases were made, in which people were shown a picture of a child with smallpox and were asked whether anyone had seen a person with such a rash. Helicopters were used to reach remote valleys in mountainous country. All of these operations were complicated by a host of natural and political problems - floods, drought, famine, war, incompetence, dishonesty, personal antagonisms, shortage of local resources and lack of cooperation.

Success is attributed to four main factors: a central international organization which had the ability to express policy directly and firmly to governments; a dedicated and competent national and international staff, willing and able to adapt and to innovate; a plan based on principles and methodologies, not directives, so that operations in each country were different, and changed appropriately as the campaign progressed; and appreciation of the need for continuing field and laboratory research, and the availability of strong international technical support (which was freely given).

Eradication is a bold word. What are the chances of the reappearance of smallpox? After ten years, the virus is unlikely to have remained undetected in the field, either in man or in any other primate that, on close contact with man, has been shown to be susceptible. Monkeypox caused concern when it appeared in West and Central Africa during the 1970s, but DNA analysis showed that it differs from variola virus, for which there appears to be no animal reservoir. In China, Afghanistan, Pakistan and Ethiopia, where variolation was widely practised by traditional experts, any remaining reserves of scabs from smallpox lesions are unlikely still to be infective and the chance of virus surviving in corpses, even those buried in the permafrost, is regarded as remote. Laboratory stocks of variola virus clearly constitute a risk, as shown by the outbreak in a Birmingham laboratory in 1978; strenuous efforts have been made to destroy all the remaining samples lurking in laboratory deep-freezers. The only reserves of virus are kept for reference in two maximum-security freezers, one in Moscow and one in Atlanta, Georgia.

There remains the possibility of deliberate release, although smallpox, because of its slow spread by face-to-face contact, is not an ideal biological weapon. Nevertheless, there is always a chance that some idiot might one day use the virus to threaten an unvaccinated world. As the authors conclude:

it is melancholy but perhaps realistic to suggest that the possibilities of biological warfare or terrorism now constitute the chief reason for holding reserves of vaccine and for maintaining epidemiological and laboratory expertise for the diagnosis and control of smallpox.

In a world of nuclear weapons and other menaces it is good to see that science at its best, backed by effective organization, can really work to the benefit of mankind. Arthropod-borne diseases with reservoir hosts, and those that depress or fail to stimulate the immune response, will be less easy to conquer. But the pattern of success has been established and WHO should face the future with renewed confidence.

Len Goodwin, Wellcome Trust Film Unit, 183 Euston Road, London NW1 2BP, UK, was formerly Director of the Wellcome Laboratories of Tropical Medicine and Director of Science at the Zoological Society of London. 